\title{
PHASE VARIATION IN THE GENUS SERRATIA
}

\author{
Viola M. Young, Marcia R. Moody and Maureen J. Morris \\ Microbiology Research Section, Baltimore Cancer Research Center, \\ National Cancer Institute, 655 W. Baltimore Street, Baltimore, \\ Maryland 21201, USA
}

CONCERN about Serratia marcescens as an infectious agent that may become resistant to many antibiotics (Schaberg et al., 1976; Traub et al., 1976; Ostenson, Fields and Nolan, 1977) has led to the investigation of techniques such as serotyping and bacteriocine typing for use as epidemiological tools. Despite the disadvantage of dominant serotypes, serotyping has remained an effective method, particularly when used in conjunction with biotyping (Rubin et al., 1976; Roemisch and Kocka, 1976) or bacteriocine typing (Roemisch and Kocka, 1976; Anderhub et $a l ., 1977)$ for the detection of differences between strains. During an investigation of $S$. marcescens serotypes in cancer patients (Young, Moody and Morris, 1980) a phenomenon that appeared to be flagellar phase variation occurred among some strains. A study of this observation is the subject of this report.

\section{MATERIALS AND METHODS}

Bacterial antigens and serotyping. Two hundred and forty-one strains of S. marcescens were serotyped. The sources of the strains, the preparation of somatic $(\mathrm{O})$ and flagellar $(\mathrm{H})$ antigens, and the serotyping techniques have been described (Young et al., 1980).

$H$-antigen immobilisation. After the strain had been passed sequentially through the three plates containing $0.4 \%, 0.6 \%$, and $0.8 \%$ of agar, material from the edge of the growth on the $0.8 \%$ motility agar plate was inoculated into $4 \mathrm{ml}$ of trypticase soy broth (TSB) which then was incubated at $37^{\circ} \mathrm{C}$ for $5 \mathrm{~h} ; 1 \mathrm{ml}$ of the culture was removed and refrigerated for subsequent use in immobilisation tests, and the rest was treated with phenol for $\mathrm{H}$-antigen determinations by tube agglutination tests. After the $\mathrm{H}$ antigenic type had been determined by tube tests (Young et al., 1980), a Gard plate (Gard, 1937) was prepared that contained antiserum against the homologous $\mathrm{H}$ antigenic type in a final dilution of 250 . This plate was inoculated with the "original TSB" culture which had been stored at $4^{\circ} \mathrm{C}$ and the plate was incubated for $24 \mathrm{~h}$ at room temperature. If motility was blocked, the $\mathrm{H}$ type found by tube agglutination was considered to be confirmed.

Demonstration of phase variation. If motility on the Gard plate was not blocked and growth still migrated from the point of inoculation, TSB broth was inoculated with the outermost edge of the growth, incubated at $37^{\circ} \mathrm{C}$ for $5 \mathrm{~h}$, and then phenolised. Agglutination tests were performed as previously described to determine the $\mathrm{H}$ antigenic type. The $\mathrm{H}$ antiserum to which this antigenic preparation reacted and the $\mathrm{H}$ antiserum to which the strain had first reacted were both incorporated into a Gard plate at a concentration of 1 in 250 for each and this plate was inoculated from the "original TSB". If motility was blocked, two H antigens were considered to be present. In rare instances, when motility was not blocked, the procedure for $\mathrm{H}$ antigenic determination by tube agglutination tests was repeated and the third $\mathrm{H}$ antiserum was incorporated into the medium with the other two. After the second, and occasionally third, $\mathrm{H}$ antigen had been determined as described, reversibility of the phases was determined by again growing the organism in the presence of the antiserum against the second or third $\mathrm{H}$ antigen or both.

\section{RESULTS}

Of the 241 strains of $S$. marcescens tested we were able to demonstrate that $21(8.7 \%)$ had 
TABLE

Association of flagellar antigens of S. marcescens with phase variation

\begin{tabular}{cc}
\hline H antigens* & Number of strains \\
\hline 1,4 & 4 \\
1,7 & 1 \\
1,10 & 3 \\
1,11 & 1 \\
$1,2,10$ & 1 \\
$1,7,11$ & 1 \\
4,5 & 1 \\
4,7 & 1 \\
4,11 & 2 \\
4,12 & 2 \\
7,10 & 1 \\
7,12 & 1 \\
10,12 & 1 \\
11,12 & 1 \\
\hline
\end{tabular}

* Strains with any of $\mathrm{H}$ antigens 3,6,8,9, and 13 did not show phase variation.

more than one $\mathrm{H}$ antigen (table). Of these strains 19 were diphasic and two were triphasic. Approximately half (11) of the strains with more than one phase had $\mathrm{H} 1$ antigen with one or more other antigens. Two strains with more than one $\mathrm{H}$ antigen had an $\mathrm{H} 4$ component; five strains each had such combinations with $\mathrm{H} 7, \mathrm{H} 10$, and $\mathrm{H} 12$; one strain with the component $\mathrm{H} 2$ and one with $\mathrm{H} 5$ also occurred.

Strains that had more than one $\mathrm{H}$ phase were obtained from a variety of sites with one third (7 strains) isolated from rectal cultures; other sources were blood, sputum and gums ( 3 strains each), necropsy (2) and platelets, throat and lesion (1 each).

\section{Discussion}

The phase variation demonstrated during these studies would not have been observed if Gard plates had not been used to confirm results of tube agglutination tests. The Gard plates were used after several similar isolates from a single patient were found to have the same $O$ antigen but different $\mathrm{H}$ antigens. After repeated subcultures and selection of isolated colonies to assure that different strains with different serotypes were not involved, it was concluded that some type of phase variation was involved.

Although such phase variation is well known for some genera among the Enterobacteriaceae, it has not been previously described for the genus Serratia. It is best known in Salmonella, described by Andrewes (1922) as a phenomenon wherein "Two well-defined types are present in every culture and apparently two only, but either may undergo transformation into the other". The variation for Salmonella is reversible; this type of variation also has been reported in the genus Arizona (Edwards and West, 1945; Fife et al., 1960). Edwards (1946) described another type of variation in Citrobacter in which the strain divided into distinct variants that did not share $\mathrm{H}$ antigens but between them contained all antigens of the parent strain and could not be reverted into their original parent form. Later, the "Hafnia" group (Deacon, 1952) and "Aerobacter cloacae" (Sakazaki and Namioka, 1960) also were demonstrated to have this kind of variation. Because the phases were readily reversed the variation observed in the present study appeared at first to be the phase variation reported by Andrewes (1922) rather than phase induction, even though it was demonstrated in the presence of homologous flagellar antisera. Further, in some instances when single colonies were streaked onto plates, and several colonies 
selected from the plates were tested separately, both phases were shown to be present as originally described by Andrewes (1922).

Later, after the same strains were stored in semisolid agar for about 6 months and retested, reversion to the naturally occurring antigens was achieved in each instance but with greater difficulty. Thus, this later reversion more closely resembled induction of phases (Fife et al., 1960) than simple variation of phases.

The expression of one flagellar antigen over another has been reported by Silverman and Simon (1977) to occur at a fixed frequency. Reverse transition to the original phase generally occurs at a different frequency (Mākelă, 1964). The phase variation of Serratia appeared to occur at a lower rate than that observed among the Salmonella. The frequency of expression of flagellar phases, the possibility of phage induction, and the type of phase variation needs further study.

\section{SUMMARY}

During an investigation of the serotypes of Serratia marcescens present in a cancer centre, it was found that $8.7 \%$ of 241 strains had more than one $\mathrm{H}$ antigen. There were 19 diphasic and two triphasic strains. Antigen $\mathrm{H} 1$ was a component of the phases in approximately half of the strains with multiple phases. This is the first report of such phases in the genus Serratia.

\section{REFERENCES}

Anderhub, B., Pitt, T. L., Erdman, Y. J. and Willcox, W. R. 1977. A comparison of typing methods for Serratia marcescens. J. Hyg., Camb., 79, 89.

ANDREwES, F. W. 1922. Studies in group-agglutination. I. The Salmonella group and its antigenic structure. J. Path. Bact., 25, 505.

DeAcon, W. E. 1952. Antigenic study of certain slow lactose fermenting Aerobacter cloacae cultures. Proc. Soc. exp. Biol. Med., 81, 165.

EDWARDS, P. R. 1946. The segregation of antigens in a bacterial culture by an undescribed form of variation. J. Bact., 51, 523.

EDWARDS, P. R. AND WeST, M. G. 1945. Phase variation of Andrewes in a coliform bacterium. J. infect. Dis., 77, 185.

Fife, M. A., Edwards, P. R., Sakazaki, R., Nozawa, M. and Murata, M. 1960. The occurrence of three flagellar phases in Arizona serotypes. Jap. J. med. Sci. Biol. 13, 173.

GARD, S. 1937. Ein Colistamm mit Salmonella- H-Antigen, zugleich ein Beitrag zur Frage der Definition der Salmonella-Gruppe. Z. Hyg. 120, 59.

MĀKELĂ, P. H. 1964. Genetic homologies between flagellar antigens of Escherichia coli and Salmonella abony. J. gen. Microbiol., 35, 503.

Ostenson, R. C., Fields, B. T. and Nolan, C. M. 1977. Polymyxin B and rifampin: new regimen for multiresistant Serratia marcescens infections. Antimicrob. Ag. Chemother., 12, 655 .

RoEmisch, E. AND Kocka, F. E. 1976. Comparison of methods for differentiating among Serratia marcescens isolated from clinical specimens. Am. J. clin. Path., 66, 96.

Rubin, S. J., Brock, S., Chamberland, M. and Lyons, R. W. 1976. Combined serotyping and biotyping of Serratia marcescens. J. clin. Microbiol., 3, 582.

SAKAZAKI, R. AND NAMIOKA, S. 1960. Serological studies on the Cloaca (Aerobacter) group of enteric bacteria. Jap. J. med. Sci. Biol., 13, 1.

Schaberg, D. R., Alford, R. H., Anderson, R., Farmer, J. J. III., Melly, M. A. and SCHAFFNER, W. 1976. An outbreak of nosocomial infection due to multiply resistant Serratia marcescens: evidence of inter-hospital spread. J. infect. Dis., 134, 181.

Silverman, M. AND Simon, M. I. 1977. Bacterial flagella. In Annual review of microbiology, 31. Annual Reviews Inc.: Palo Alto, p. 397.

Traub, W. H., Kleber, I., Puhler, A. AND Burkardt, H. J. 1976. Characterization of a nosocomially significant, multiple drug-resistant strain of Serratia marcescens. Chemotherapy, 22, 297.

Young, V. M., Moody, M. R. AND MorRIS, M. J. 1980. Distribution of Serratia marcescens serotypes in cancer patients. J. med. Microbiol., 13, 333. 